\title{
Individual adaptive capacity of small-scale fishermen living in vulnerable areas towards the climate change in Malaysia
}

\begin{abstract}
The present study attempts to identify the individual adaptive capacity of small-scale fishermen living in coastal areas that are vulnerable to the climate change in Malaysia. This study is quantitative in nature and involves a total of 240 respondents from four areas in Malaysia. It can be concluded that small-scale fishermen in Malaysia have adaptive strength in two aspects: namely formal and informal networks; and environmental awareness, values and attitudes. Although the fishermen were found to record a high mean score for three other adaptive aspectsï local environmental knowledge; attachment to job; and attachment to placeï this actually demonstrates their adaptive weaknesses. Employability is another area of concern, as it emerged as the fishermen's weakest adaptive aspect. This study demonstrates the potential of alternative skills, managed retreat, accommodation and protection, information management, periodical assessment and access to credit to produce progressive adaptive capacity of small-scale fishermen in Malaysia.
\end{abstract}

Keyword: Adaptive capacity; Community development; Fisheries development; Environmental issues; Rural development 